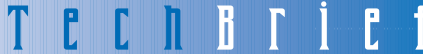

The mission of the Office of

Motor Carrier Safety is to

develop and promote, in

coordination with other

Departmental modes,

data-driven, analysis-based,

and innovative programs to

achieve continuous safety

improvements in the Nation's

highway system, intermodal

connections, and motor carrier

operations. The Office of

Motor Carrier Research and

Standards manages the

safety regulatory program

and the central research

management function for

Motor Carrier Safety.

There are eight major research

and technology focus areas:

regulatory evaluation and

reform; compliance and

enforcement; driver training

and performance manage-

ment; driver alertness and

fatigue; driver physical

qualifications; car-truck

proximity; HAZMAT safety

and cargo tank integrity; and

crash causation and profiling.

Car-truck proximity involves

studies of the interaction of

trucks with proximal "other

road users" such as cars, light

trucks, and vans.

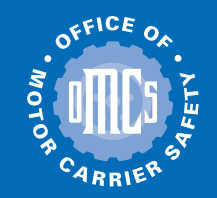

Office of Motor Carrier Research and Standards

400 Seventh Street, SW

HMCS-30; Room 3107

Washington, DC 20590
OFFICE OF MOTOR CARRIER SAFETY

Contact: Anthony Schafer, HMPC-10, (202) 366-2953

\section{The Unsafe Driving Acts of Motorists in the Vicinity of Large Trucks}

\section{Introduction}

The fatal crash rate of large trucks has declined significantly over the past decade, from more than 4 per million miles driven during the 1980s, to approximately 2.5 per million miles traveled now. In 1996, large trucks composed 8 percent of all vehicles involved in fatal crashes; however, truck-involved crashes resulted in 12 percent of the total fatalities. Occupants of large trucks compose only 14 percent of the fatalities resulting from fatal truck crashes; 86 percent of the fatalities occur outside the truck, to pedestrians, cyclists, and primarily, the occupants of passenger vehicles. The greater mass of large trucks better absorbs the energy generated in a collision, leaving a smaller vehicle at a disadvantage.

By identifying driving behaviors that lead to collisions between passenger vehicles and large trucks, countermeasures can be developed to further reduce the incidence and severity of crashes. This tech brief summarizes a study concerning unsafe driving acts (UDAs) of motorists in the vicinity of large trucks. UDAs are defined as motorist behaviors that contribute to collisions. The study final report will be available from the National Technical Information Service.

\section{Purpose}

The purpose of this initiative was to identify UDAs of motorists in the vicinity of large trucks as contributing factors in fatal truck crashes, in order to target these behaviors and develop countermeasures. Additional objectives included the development of recommendations for training materials and possible changes to the Uniform Vehicle Code and Model Traffic Ordinance (UVCMTO).

\section{Methodology}

The project comprised several research tasks, including: 1) review and analysis of statistical crash data; 2 ) interviews with truck drivers, collision investigators, and other experts; 3) review and analysis of collision investigation reports; and 4) a systematic rating of the UDAs by a sample of experts.

Researchers reviewed statistical summaries of crash data to identify the types of trucks and roadways that are most involved in fatal collisions. The primary source of data used during this project task was the U.S. Department of Transportation's Fatality Analysis Reporting System (FARS). FARS data were obtained for the year 1995, the most recent complete year at the time of the analysis. Collision investigation reports from seven States were also reviewed, and researchers tabulated the primary collision factors for collisions in which the driver of a passenger vehicle contributed to the crash.

Open-ended interviews with subject matter experts were conducted to identify the UDAs of motorists that lead to collisions with large trucks. The participating experts included truck drivers, collision investigators, and Federal and State officials. A panel 
of experts then ranked the identified UDAs in order of frequency and danger.

A rating instrument/form was developed to permit experts to assign values to each UDA with respect to how dangerous a behavior is, and how frequently it occurs. Each UDA was presented along with two 10 -point scales. The first scale asked respondents to estimate the danger of the act, defined as a combination of the probability and severity of a collision when committed by a motorist in the vicinity of a large truck. The second scale asked respondents to estimate the frequency with which the driving act occurs. Rating forms were sent to 25 subject matter experts and were returned by 21 .

\section{Findings}

The lists of unsafe driving acts resulting from the statistical reviews, interviews with experts, and review of collision investigation reports were used to develop a final list of UDAs, including:

- Changing lanes abruptly in front of a truck

- Driving left of center

- Following too closely

- Unsafe passing, primarily with insufficient headway

- Unsafe speed

- Merging improperly

- Driving between large trucks

The experts reported that the condition most common in collisions involving passenger vehicles and large trucks is motorists' unfamiliarity with the performance limitations and capabilities of large trucks. It appeared that most drivers are unaware of the limited acceleration, braking, and visibility of large trucks and of the relationship between mass and velocity and the potential consequences of that relationship to safety. Particularly distressing to truck drivers is when a motorist passes a large truck, quickly cuts in front of it, then exits the highway.

Table 1 presents the first 10 UDAs listed in descending order of danger, and Table 2 presents the first 10 UDAs in order of their frequency, as determined by the experts' rating. Standard deviations from the mean were calculated for all UDAs. This procedure found considerable agreement among experts concerning the relative danger of the UDAs, but greater variance in their ratings of frequency.

In order to reflect both the relative danger and relative frequency of each UDA, researchers combined the mean scores for the two categories in a separate metric, labeled criticality. Criticality values placed equal weight on the expert's ratings of danger and frequency; the first 10 UDAs in descending order of criticality are presented in Table 3.

Using the criticality metric, driving behaviors that were considered extremely dangerous, but infrequent, could reasonably be compared to UDAs that are only moderately dangerous, but happen more frequently. For example, experts rated "Following too closely" as the most frequent of the UDAs, but placed it 17th in terms of danger; the composite ranking places it sixth on the criticality list. Experts rated "Driving inattentively" as the seventh most dangerous UDA and the third most frequent, placing it at the top of the criticality list.

\begin{tabular}{|l|l|}
\hline \multicolumn{1}{|c|}{$\begin{array}{c}\text { Table 1. } \\
\text { Uean Score: } \\
\text { Danger }\end{array}$} & \multicolumn{1}{c|}{ Unsafe Driving Act } \\
\hline 9.67 & Driving left of center or into opposing traffic \\
\hline 9.62 & Unsafe passing, primarily passing with insufficient headway \\
\hline 9.52 & Driving while impaired by alcohol or other drug \\
\hline 9.14 & Failure to stop for a stop sign or light (also, early or late through a signal) \\
\hline 8.95 & Failure to discern that the trailer of a maneuvering truck is blocking the roadway \\
\hline 8.90 & Unsafe crossing, primarily crossing traffic with insufficient headway \\
\hline 8.76 & Driving inattentively (e.g., reading, talking on phone, fatigue-induced inattention) \\
\hline 8.76 & Merging improperly into traffic, causing a truck to maneuver or brake quickly \\
\hline 8.76 & Pulling into traffic from roadside in front of a truck without accelerating sufficiently \\
\hline 8.71 & Unsafe turning, primarily turning with insufficient headway \\
\hline
\end{tabular}




\section{Conclusions/Recommendations}

By reviewing relevant statistical summaries, interviewing a representative sample of subject matter experts, recording contributing factors from a large sample of collision investigation reports, and conducting a systematic rating procedure, researchers compiled an ordered list of the UDAs of motorists in the vicinity of large trucks. Unfamiliarity with performance limitations of large trucks appeared to be a contributing factor to many of the unsafe acts of motorists.
Researchers recommended that the results of the study be applied to the development of training materials for truck drivers, drivers of passenger vehicles, and law enforcement officers. In developing training materials for truck drivers, the list of UDAs in table 3 could serve as a checklist of the motorist behaviors of which truck drivers must remain aware while on the road. To remedy motorist unfamiliarity with the performance limitations of large trucks, researchers suggest that public information and education programs be developed to illustrate the

\begin{tabular}{|c|c|}
\hline & $\begin{array}{l}\text { Table } 2 . \\
\text { Unsafe Driving Acts: Experts' Rating of Frequency }\end{array}$ \\
\hline $\begin{array}{l}\text { Mean Score: } \\
\text { Frequency }\end{array}$ & Unsafe Driving Act \\
\hline 8.05 & Following too closely \\
\hline 8.00 & Unsafe Speed (e.g., approaching too fast from the rear, misjudging truck speed) \\
\hline 7.90 & Driving inattentively (e.g., reading, talking on phone, fatigue-induced inattention) \\
\hline 7.76 & Driving in the "No-Zones" (left rear quarter, right front quarter, and directly behind) \\
\hline 7.67 & Merging improperly into traffic, causing a truck to maneuver or brake quickly \\
\hline 7.62 & Failure to slow down in a construction zone \\
\hline 7.48 & $\begin{array}{l}\text { Failure to slow down in response to environmental conditions (e.g., fog, smoke, rain, } \\
\text { bright sun) }\end{array}$ \\
\hline 7.10 & Failure to stop for a stop sign (also, early or late through a signal) \\
\hline 7.10 & Changing lanes abruptly in front of a truck \\
\hline 6.71 & Changing lanes in front of a truck, then braking (for traffic, obstacle, toll gate, etc.) \\
\hline
\end{tabular}

Table 3.

Unsafe Driving Acts: Experts' Rating of Criticality (Danger + Frequency)

\begin{tabular}{|c|l|}
\hline $\begin{array}{c}\text { Combined } \\
\text { Mean Scores }\end{array}$ & \\
\hline 16.67 & Driving inattentively (e.g., reading, talking on phone, fatigue-induced inattention) \\
\hline 16.43 & Merging improperly into traffic, causing a truck to maneuver or brake quickly \\
\hline 16.24 & Failure to stop for a stop sign or light (also, early or late through a signal) \\
\hline 16.19 & Failure to slow down in a construction zone \\
\hline 16.05 & Unsafe speed (e.g., approaching too fast from the rear, misjudging truck speed) \\
\hline 15.95 & Following too closely \\
\hline 15.86 & $\begin{array}{l}\text { Failure to slow down in response to environmental conditions (e.g., fog, smoke, rain, } \\
\text { bright sun) }\end{array}$ \\
\hline 15.67 & Changing lanes abruptly in front of a truck \\
\hline 15.43 & Driving in the "No-Zones" (left rear quarter, right front quarter, and directly behind) \\
\hline 15.29 & Unsafe passing, primarily passing with insufficient headway \\
\hline
\end{tabular}




\section{Researcher}

This study was performed by Anacapa Sciences, Inc., Santa Barbara, CA 93102. Contract No. DTFH61-97-C-00090.

\section{Distribution}

This Tech Brief is being distributed according to a standard distribution. Direct distribution is being made to the Resource Centers and Divisions.

\section{Availability}

The study final report will be available from the National

Technical Information Service, Telephone: (703) 605-6000.

\section{Key Words}

trucks, unsafe driving, law enforcement, collisions, highway safety, commercial motor vehicles.

\section{Notice}

This Tech Brief is disseminated under the sponsorship of the Department of Transportation in the interest of information exchange. The Tech Brief provides a synopsis of the study's final publication. The Tech Brief does not establish policies or regulations, nor does it imply USDOT endorsement of the conclusions or recommendations. The U.S. Government assumes no liability for its contents or their use.

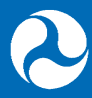

U.S. Department of Transportation acceleration, braking, and turning limitations of trucks. It was also recommended that training materials for law enforcement officers help distinguish between driving acts that are code violations, such as "Following too closely," and those that are unsafe but not illegal, such as "Driving in the No-Zones." Training materials should also help sensitize officers to the dangers associated with UDAs.

Another objective of the current study was to explore the possibility of implementing changes to vehicle codes that would permit officers to cite drivers for unsafe driving practices that currently are not vehicle code violations. The recommended method for encouraging changes to vehicle codes is to propose that the changes be made to the Uniform Vehicle Code and Model Traffic Ordinance (UVCMTO).

The UVCMTO was written to provide States with a model to use in developing traffic citations; however, it does not specifically address the issue of UDAs of passenger vehicles in the vicinity of trucks. Researchers suggested that special consideration or penalties are warranted when UDAs are committed in the vicinity of large trucks, because of the greater possibility of serious injury or fatalities resulting from collisions between passenger vehicles and large trucks, compared to collisions between passenger vehicles. 